\title{
La iniciativa emprendedora como base para la creación de empresas de participación: un instrumento para la innovación social
}

\author{
Paloma Bel-Durán*, Josefina Fernández-Guadaño ${ }^{\star *}$, Gustavo Lejarriaga-Pérez de las Vacas ${ }^{\star * *}$, \\ Sonia Martín-López ${ }^{\star * * *}$
}

* Doctora en Ciencias Económicas y Empresariales. Profesora titular, Facultad de Ciencias Económicas y Empresariales, Universidad Complutense de Madrid, España.

Correo electrónico: pbeldura@ucm.es

* Doctora en Ciencias Económicas y Empresariales. Profesora contratada, Facultad de Ciencias Económicas y Empresariales, Universidad Complutense de Madrid, España.

Correo electrónico: jofernan@ucm.es

*** Doctor en Ciencias Económicas y Empresariales. Profesor titular, Facultad de Ciencias Económicas y Empresariales, Universidad Complutense de Madrid, España.

Correo electrónico:

lejavaca.gus@ccee.ucm.es

${ }^{* * * *}$ Doctora en Ciencias Económicas y

Empresariales. Profesora contratada

Facultad de Ciencias Económicas y

Empresariales, Universidad Complutense de Madrid, España.

Correo electrónico: smartin@ucm.es

Recibido: 26 de septiembre del 2015 Aceptado: 9 de noviembre del 2015

Cómo citar este artículo: Bel-Durán, P., Fernández-Guadaño, J., Lejarriaga-Pérez de las Vacas, G., Martín-López, S. (2016). La iniciativa emprendedora como base para la creación de empresas de participación: un instrumento para la innovación social. Cooperativismo y Desarrollo, 24(108), 121-141. doi: http://dx.doi.org/10.16925/ co.v24i108.1267

\section{Resumen}

Propósito: mostrar los resultados de un estudio que procura analizar en qué medida se promueve en la enseñanza primaria y secundaria, ya no la creación de empresas en general, sino la creación de empresas de participación, en particular. Temas: se pretende ahondar en el análisis de la correlación existente entre las iniciativas desarrolladas bajo fórmulas participativas en los centros de enseñanza cooperativos con dos objetivos más ambiciosos. El primero, contrastar si estos promueven, en mayor medida, la creación de sociedades cooperativas y laborales que otros centros educativos que no sean sociedades cooperativas. El segundo, conocer en el ámbito universitario la influencia que puedan tener los centros de educación cooperativos en la posible creación de empresas bajo fórmulas jurídicas de sociedad cooperativa y sociedad laboral. Desarrollo: se ha constatado la necesidad de una evidente coordinación de las materias y competencias en todos los niveles educativos en materia emprendedora. Conclusiones: es importante incentivar la creación y puesta en marcha de proyectos empresariales de participación en niveles inferiores de enseñanza, y que sea la universidad (las oficinas técnicas universitarias de apoyo en materia de creación de empresas y el profesorado) la que culmine el proceso de apoyo y seguimiento de estos proyectos, prestándoles asesoramiento y formación.

Palabras clave: cooperativas de enseñanza, cultura emprendedora, empresas de participación, iniciativa emprendedora. 


\title{
Entrepreneurship as the Basis for Creating Employee- Owned Companies: An Instrument for Social Innovation
}

\begin{abstract}
Purpose: To show the results of a study that intended to analyze to what extent not only the creation of businesses in general, but also the creation of employee-owned companies in particular, is promoted in primary and secondary education. Topics: It aims to delve into the analysis of the existing correlation among initiatives developed under cooperative forms in cooperative education centers with two more ambitious goals. First, to see whether they promote, to a greater extent, the creation of cooperatives and employee-owned companies compared to other schools that are not cooperatives. Second, to know at the university level the influence cooperative education centers may have in the possible creation of companies under the legal forms of cooperatives and employee-owned companies. Development: The need for a clear coordination of subjects and skills at all educational levels in terms of entrepreneurship has been confirmed. Conclusions: It is important to encourage the creation and implementation of cooperative business projects at lower levels of education, and that the university (entrepreneurship technical support offices and faculty) completes the process of supporting and monitoring these projects by providing advice and training.
\end{abstract}

Keywords: learning cooperatives, entrepreneurial culture, employee-owned companies, entrepreneurship.

\section{A iniciativa empreendedora como base para a criação de empresas de participação: um instrumento para a inovação social}

\section{Resumo}

Propósito: mostrar os resultados de um estudo que procura analisar em que medida se promove no ensino fundamental e médio já não a criação de empresas em geral, mas sim a criação de empresas de participação, em particular. Temas: pretende-se aprofundar na análise da correlação existente entre as iniciativas desenvolvidas sob fórmulas participativas nos centros de ensino cooperativos com dois objetivos mais ambiciosos. O primeiro, contrastar se estes fomentam, em maior medida, a criação de sociedades cooperativas e corporativas do que outros centros educativos que não sejam sociedades cooperativas. O segundo, conhecer no âmbito universitário a influência que os centros de educação cooperativos possam ter na possível criação de empresas sob fórmulas jurídicas de sociedade cooperativa e sociedade corporativa. Desenvolvimento: constatou-se a necessidade de uma evidente coordenação das matérias e das competências em todos os níveis educativos em matéria empreendedora. Conclusões: é importante incentivar a criação e a realização de projetos empresariais de participação em níveis inferiores de ensino, e que seja a universidade (os departamentos técnicos universitários de apoio em matéria de criação de empresas e o professorado) a que culmine o processo de apoio e seguimento desses projetos, prestando assessoria e formação a eles.

Palavras-chave: cooperativas de ensino, cultura empreendedora, empresas de participação, iniciativa empreendedora. 


\section{Introducción}

En la coyuntura actual del mercado de trabajo español, con una tasa de paro que ha pasado en los últimos años del 8,5 al 22,7\%, y donde la tasa de desempleo juvenil (menores de veinticinco años) supera el 49,2\% (con una dispersión significativa según el nivel de formación), la opción del trabajo por cuenta propia aparece como una alternativa a considerar tanto para la reinserción como para el acceso por primera vez al trabajo.

En efecto, el contexto actual en España requiere necesariamente fomentar entre los jóvenes la cultura de crear empresas. Tras años de crecimiento y de un aumento en el nivel de vida generalizado, el panorama es desalentador:

1. Deterioro de la actividad económica que afecta al ritmo de creación de nuevas empresas que empieza a hacerse menos evidente a partir del 2014 y a incrementarse lentamente en los primeros trimestres del 2015 según los datos del Directorio Central de Empresas (DIRCE) facilitados por el Instituto Nacional de Estadística.

2. Pérdida de tejido productivo con un peso muy reducido de la industria.

3. Elevado nivel de endeudamiento tanto de las familias como de las empresas.

4. Y como colofón, la elevada tasa de desempleo a la que se hacía referencia más arriba.

Si bien la opción de emprender está afectada por obstáculos y dificultades, la alternativa de hacerse empresario y hacerlo, además, en red, bajo fórmulas de participación (sociedades cooperativas y laborales) y empresarios individuales, ha de ser contemplada como la vía para contribuir a la dinamización de la economía, como la posibilidad de ser capaces de transformar las circunstancias económicas desfavorables en una oportunidad como han demostrado en recesiones previas, y sobre todo, como un mecanismo de reducción de riesgos.

Es imprescindible romper barreras informativas, culturales, empresariales y proponer políticas incentivadoras e impulsoras de la creación de un tejido empresarial consolidado; no obstante, resulta crucial la formación.

Es necesario (aunque no suficiente) generar un ambiente cultural en el que ser empresario, bajo la forma jurídica que sea, sea valorado socialmente, esto es, hemos de dotarnos de una cultura emprendedora actualmente escasa e incluso inexistente. En efecto, la falta de iniciativa emprendedora está vinculada directamente a la percepción negativa que de los empresarios se tiene en la sociedad por lo que la formación y la financiación son los factores fundamentales que influyen negativamente en la iniciativa empresarial.

Las empresas de participación (sociedades cooperativas y sociedades laborales) son una forma natural de emprender con una demostrada aportación en épocas de crisis económicas y con unas características (no deslocalización, contribución al desarrollo, mayor compromiso y cohesión, entre otras) que las hacen atractivas como fórmulas generadoras de riqueza. Sin embargo, los estudios realizados desde la universidad ponen de manifiesto un desconocimiento generalizado de este tipo de empresas, y en particular, por parte de los estudiantes. El resultado es una percepción negativa de estas formas jurídicas que provoca que se prefiera optar por la puesta en marcha de iniciativas empresariales mediante las formas jurídicas consideradas convencionales.

La cultura acerca del empresario requiere un marco adecuado para promover y potenciar la formación de estas formas jurídicas no solo en la universidad, con un papel crucial mediante la incorporación en los planes de estudios de materias específicascuya oferta sigue siendo limitada-, y la creación de estructuras de apoyo, sino también su promoción y fomento desde los niveles educativos previos.

Este trabajo procura establecer el marco adecuado para generar una oferta formativa que procure el impulso a la creación de sociedades cooperativas y laborales sobre la base de colaboración entre los distintos niveles de enseñanza. Es decir, se pretende crear un marco teórico y metodológico para estudiar en qué medida en la enseñanza secundaria se promueve ya no la creación de empresas en general, a través de la asignatura de iniciativa emprendedora, sino la creación de empresas de participación, en particular.

\section{Objetivos y metodología}

\section{Objetivos}

Se procura realizar un análisis que estudie en qué medida en la enseñanza primaria y secundaria se promueve ya no la creación de empresas en general, sino la creación de empresas de participación, en particular. De este modo, se pretende ahondar en el análisis de la correlación que pudiera existir entre las iniciativas desarrolladas bajo fórmulas participativas 
en aquellos centros de enseñanza cooperativos con dos objetivos más ambiciosos:

- El primero, contrastar si estos centros promueven en mayor medida la creación de sociedades cooperativas y laborales que otros centros educativos que no sean sociedades cooperativas.

- El segundo, conocer en el ámbito universitario, la influencia que puedan tener los centros de educación cooperativos en la posible creación de empresas bajo fórmulas jurídicas de sociedad cooperativa y sociedad laboral.

\section{Metodología}

El presente trabajo resume las conclusiones y propuestas de actuación que provienen de un proyecto de investigación titulado "Necesidad de medidas para impulsar la creación de las empresas de participación desde los diferentes niveles de enseñanza" derivado de un convenio firmado por la Unión de Cooperativas de Enseñanza de Trabajo Asociado de Madrid (Ucetam) y la Escuela de Estudios Cooperativos de la Universidad Complutense de Madrid.

Para la consecución de los objetivos establecidos, se toma el pulso, a través de un proceso de encuestación, a los estudiantes de enseñanza secundaria (y formación profesional) y a los profesores de las asignaturas de iniciativa emprendedora en centros cooperativos tratando de conocer:

- Si en los planes de viabilidad o simulación de proyectos empresariales se contempla la opción de emprender bajo fórmulas participativas.

- El grado de conocimiento del que disponen antes y después de haber cursado la asignatura.

- La correlación que pueda existir entre la imagen que tienen los alumnos y el grado de conocimiento sobre las empresas de participación así como la percepción del entorno más próximo de los alumnos.

- El grado de conocimiento e involucración de profesores que imparten estas asignaturas así como el nivel de conocimientos específicos.

- El apoyo desde el propio centro a la creación de empresas.

Este trabajo se circunscribe al ámbito de la Comunidad de Madrid, en concreto a las sociedades cooperativas asociadas a Ucetam, y más concretamente a aquellos centros en los que se imparte la asignatura de iniciativa emprendedora. De este modo, se tienen en cuenta del total de sociedades cooperativas de educación que atendiendo a la participación de los socios en el proceso productivo pueden resultar ser de proveedores, consumidores o mixtas o integrales, solo las de trabajo asociado de Madrid y, en concreto, las asociadas a Ucetam.

No obstante, no se descarta:

- En el ámbito geográfico de la Comunidad de Madrid, poder realizar un estudio comparado entre las cooperativas asociadas a Ucetam que imparten la asignatura de iniciativa emprendedora y las que no lo hacen.

- Ampliar el ámbito geográfico, generalizar el estudio a nivel nacional.

A este respecto, las figuras 1-4 ponen de manifiesto la tipología de las sociedades cooperativa en general y en la Comunidad de Madrid, en particular.

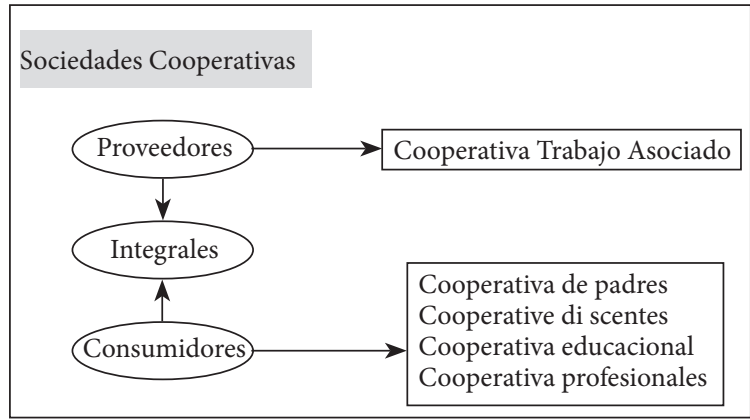

Figura 1. Clasificación de las sociedades cooperativas de enseñanza según la participación del socio en el proceso educativo. Tomada de Estudio de los flujos económico-financieros de las sociedades cooperativas en la educación: un enfoque de concentración empresarial, por J. Fernández Guadaño, 2001, p. 58.

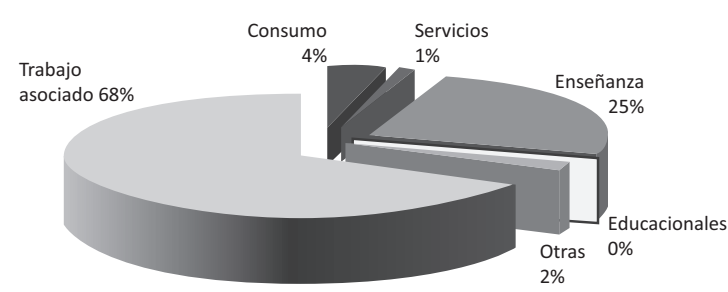

Figura 2. Tipología de las sociedades cooperativas en la educación en España. Tomada de "La realidad actual de las sociedades cooperativas en la educación", por J. Fernández Guadaño, 2000, en REvesco, Revista de Estudios Cooperativos, 71, p. 63. 


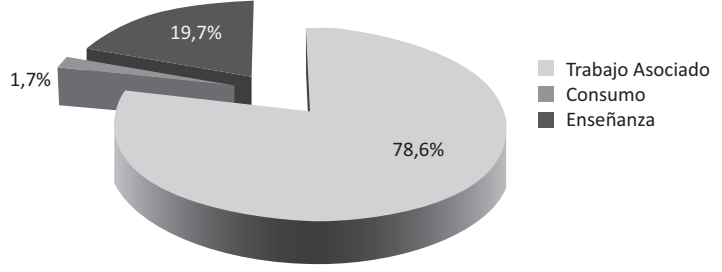

Figura 3. Tipología de las sociedades cooperativas en la educación en Madrid. Elaboración propia.

Como puede observarse, la distribución de sociedades cooperativas es muy similar en ambos casos con una fuerte presencia de las sociedades cooperativas de trabajo asociado en la educación que es sensiblemente superior en la Comunidad de Madrid.

La población objeto de estudio se concreta en la totalidad de los colegios asociados a la Unión de Cooperativas de Enseñanza de Trabajo Asociado de Madrid (Ucetam) que imparten la asignatura de Iniciativa Emprendedora que se corresponden con el 21\% de los centros que imparten Formación Profesional y el $13,41 \%$ de los centros que imparten la asignatura en la Enseñanza Secundaria Obligatoria (ESO).

El índice de respuesta ha sido del $72,7 \%$, por término medio en los tres colectivos. Teniendo en cuenta, además, que no existe el denominado sesgo de no respuesta habida cuenta de que el colectivo que no ha contestado no difiere en sus características de los que sí lo hicieron al tratarse de una población muy homogénea, se puede llegar a concluir que la valoración de las respuestas obtenidas es significativa de la opinión del colectivo.

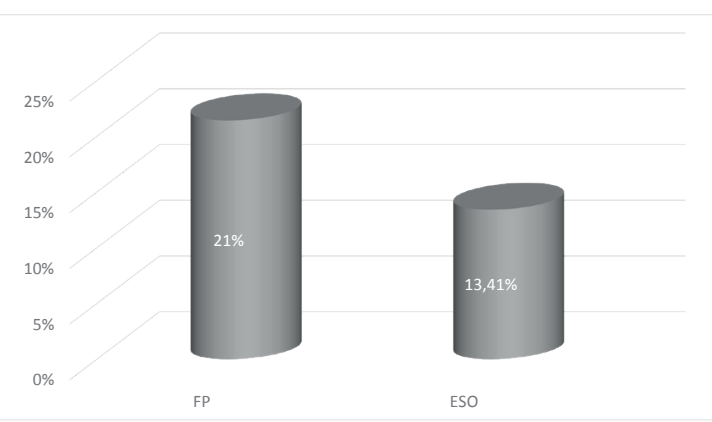

Figura 4. Porcentajes de centros asociados a Ucetam que imparten la asignatura de iniciativa emprendedora. Elaboración propia.

El presente estudio ha constado de varias etapas que se explican a continuación.

En la primera etapa se realizó un estudio del marco teórico, la normativa que afecta al objeto de estudio, el análisis de la realidad, los retos con los que nos enfrentamos y las perspectivas de futuro. Para todo ello se analizan referencias bibliográficas básicas y específicas que se relacionan al final del documento.

El estudio teórico ha dado lugar a diferentes artículos y ponencias presentados en seminarios y congresos científicos nacionales e internacionales (Martín López, Fernández Guadaño, Bel Durán y Lejarriaga Pérez de Las Vacas, 2013, 2014; Martín López, Fernández Guadaño, Bel Durán y Lejarriaga Pérez De Las Vacas, García-Gutiérrez Fernández, 2013, 2014).

En la segunda etapa, se elaboraron tres cuestionarios:

1. Un primer cuestionario para alumnos de $4^{\circ}$ de la eso y formación profesional que estudian la asignatura Iniciativa Emprendedora.

2. Un segundo cuestionario para los profesores que imparten la asignatura de Iniciativa Emprendedora.

3. Un tercer cuestionario a los responsables de los centros en los que se imparte dicha asignatura.

Entre otros, se pretende valorar la opinión sobre los siguientes asuntos:

- El emprendimiento en general.

- La creación de empresas en particular.

- Los aspectos específicos de la asignatura de iniciativa emprendedora.

- Los procesos de simulación de creación de empresas.

- El conocimiento de las empresas de participación (desde el punto de vista teórico).

- La valoración de los alumnos con respecto a los conocimientos adquiridos.

- Las perspectivas de futuro.

- El grado de involucración de los profesores.

La tercera fase ha consistido en la selección de la población objeto de estudio que se concreta en los diecinueve de los noventa colegios asociados a la Ucetam que imparten la asignatura de iniciativa emprendedora.

Así, una vez definido el objeto de estudio, diseñado el cuestionario (con preguntas precisas y cuantificables), y seleccionada la población objeto de estudio, aspectos fundamentales para garantizar la calidad de la investigación, se ha procedido a informar a los responsables de los centros sobre el proyecto de investigación y a solicitar su colaboración con el envío a través de correo electrónico de los cuestionarios. 
La última fase es la explotación y la elaboración de informes cuyos aspectos más destacados se presentan, derivados de los cuales se han concretado las conclusiones y propuestas de actuación.

\section{La percepción del emprendimiento de participación por parte de los estudiantes de la asignatura de iniciativa emprendedora}

El estudio que se desarrolla atendiendo a la clasificación por sexo se reparte en un 54\% hombres y el $46 \%$ mujeres.

\section{El emprendimiento y la creación de empresas}

Los alumnos valoran bastante casi todas las iniciativas que en materia emprendedora se les han planteado pero la que obtiene una mayor puntuación es la de simulación de empresas con fines educativos; seguida de la creación y gestión (por parte de los alumnos) de sus propias empresas, y comercialización de sus productos con otras empresas ubicadas en otras regiones de España o en otros países. Con una menor valoración, le siguen la realización de jornadas y talleres de sensibilización para fomentar el espíritu emprendedor y la difusión de material didáctico de carácter lúdico y participativo para dar a conocer ejemplos de empresarios; las visitas guiadas a empresas y viveros de empresas; las visitas de empresarios al aula que cuenten a los alumnos su propia experiencia y, por último, los concursos de ideas empresariales y organización de olimpiadas de emprendedores.

De los objetivos en materia de cultura emprendedora, los estudiantes valoran, en primer lugar, la creatividad para encontrar una idea de negocio propia; en segundo lugar, entender el concepto de espíritu emprendedor y actitud emprendedora; y en tercer lugar, conocer los recursos clave para crear una empresa/proyecto emprendedor: financieros, humanos y de información y saber cuáles se necesitan en cada caso concreto.

Los estudiantes consideran prioritarios, entre los contenidos que deben ser tenidos en cuenta por el colegio para formarles en la cultura del emprendimiento, en primer lugar, el espíritu emprendedor y las actitudes hacia la actividad emprendedora; después, el papel de la creatividad; y en tercer lugar, conocer los factores de éxito y de fracaso de los proyectos empresariales. Valoran más las actitudes hacia el emprendimiento que cuestiones técnicas como el plan de empresa, los recursos en el proceso emprendedor o el estudio de las diversas formas jurídicas. En este sentido, valoran sobre todo la capacidad creativa e innovadora, el compañerismo y la motivación como principales actitudes relacionadas con el emprendimiento.

Respecto a los factores que influyen en la decisión de emprender, los alumnos valoran, en primer lugar, tener mejores posibilidades de desarrollo profesional, seguido de la autorrealización personal, y en tercer lugar, de la existencia de oportunidades de mercado.

Los estudiantes consideran que las ventajas más importantes de ser emprendedor son, en este orden, la independencia, libertad de decisión y control del negocio, seguidas de, satisfacción personal (autorrealización), y de la posibilidad de obtener mayores ingresos que como trabajador asalariado. Hay un pequeño porcentaje que señala entre otras ventajas la visión global del mercado, la mayor creatividad, y la autoestima. Respecto de los inconvenientes de ser emprendedor, los alumnos destacan en primer lugar, el riesgo, la incertidumbre sobre las perspectivas de crecimiento y consolidación de la empresa y las dificultades en la consecución de los recursos financieros necesarios.

Cuando pretendemos conocer el interés de los estudiantes en la creación de empresas, observamos que la respuesta mayoritaria con un $42 \%$ es regular; mientras que, un $29 \%$ considera que bastante; y un $19 \%$ que mucho. Siendo minoritario el porcentaje (11\%) que dice que no tiene interés. Para tratar de evitar su indecisión, preguntamos a los discentes por las medidas que consideran que se podrían llevar a cabo en su colegio para aumentar su interés por la creación de empresas, el 18,64\% destaca la realización de visitas guiadas a empresas; el 17,98\% la invitación a expertos externos y profesionales del mundo empresarial a las aulas, que cuenten su experiencia como emprendedores; y el 16,37\% la utilización de programas de simulación de empresas.

Casi el 70\% de los estudiantes reconocen que se dedica entre poco y muy poco a la atención del espíritu empresarial y la creación de empresas en la Enseñanza Primaria y Secundaria. Un resultado preocupante que implica la necesidad de tomar medidas para corregir la situación. Tan solo un 19\% cree que se dedica mucha atención y un $11 \%$ que no se dedica nada. 
El 84\% de los estudiantes considera que la enseñanza sobre el emprendimiento y creación de empresas debe formar parte de los programas de formación de los niveles educativos de primaria y secundaria. Llama la atención que un porcentaje muy similar, el $86 \%$, manifiesta haberse planteado alguna vez su futuro profesional. Y entre las salidas profesionales que han pensado para su futuro, parece que les está afectando mucho la situación que vivimos actualmente en nuestro país, que con tasas de desempleo juvenil del $52 \%$, está obligando a los jóvenes a buscar oportunidades fuera de España, porque la primera opción más valorada por los estudiantes es la de trabajar en una empresa fuera de España, en segundo lugar, crear su propia empresa, y en tercer lugar, trabajar para una multinacional en España.

\section{Los aspectos específicos de la asignatura de iniciativa emprendedora}

El 56\% de los estudiantes considera que la asignatura de Iniciativa Emprendedora debe seguir siendo optativa; frente al $25 \%$ que cree que debería ser obligatoria; o por el contrario, el $14 \%$ que no debe serlo. El $83 \%$ de los estudiantes manifiesta que en la asignatura de Iniciativa Emprendedora simulan la creación de una empresa, frente al 17\% que sostienen que no. Les hemos preguntado si en la asignatura Iniciativa Emprendedora se promueven de forma específica la creación de sociedades cooperativas y sociedades laborales, que tiene un doble valor si consideramos que los estudiantes son de sociedades cooperativas de enseñanza, y el $46 \%$ manifiesta que regular, el $42 \%$ que cree que bastante o mucho, frente al $12 \%$ que considera que muy poco o nada.

Los alumnos consideran mayoritariamente (66\%) que el perfil no es determinante a la hora de escoger la asignatura de Iniciativa Emprendedora, mientras que el $20 \%$ cree que lo hacen más los de ciencias sociales, y el 13\% que los de ciencias y tecnología. Los que han cursado la asignatura Iniciativa Emprendedora creen mayoritariamente que el programa tiene los objetivos bien definidos, que la asignatura se basa en la puesta en marcha de un proyecto empresarial por parte de los estudiantes, que gracias a ello se mejoran sus capacidades para trabajar en equipo, resolver problemas y descubrir oportunidades, que se promueve la creatividad, la iniciativa, la asunción de riesgos, o la responsabilidad, entre otras, y que, por tanto, la asignatura les ayuda a gestionar y dirigir una empresa.
Sin embargo, la mayoría también considera que en la asignatura no existe un equilibrio adecuado entre las explicaciones teóricas y las actividades prácticas; que no se invitan a las clases a emprendedores que cuentan su experiencia; que no se realizan visitas guiadas a empresas; que no se establecen relaciones con otras iniciativas empresariales puestas en marcha por alumnos de otros centros de España, o del extranjero, y que no se promueven concursos para premiar los mejores proyectos empresariales.

Los estudiantes creen que las ventajas que tiene simular un proyecto empresarial es que les permite aprender a trabajar en equipo (25\%); mostrar su capacidad creativa e innovadora (20\%); aprender a tomar decisiones (20\%); aprender a responsabilizarse de sacar adelante un proyecto empresarial (21\%); y en último lugar, lo menos valorado, con un $13 \%$, es que cursar la asignatura les genere inquietud para en el futuro poder crear su propia empresa, seguramente, motivados porque todavía les quedan bastantes años para acabar su formación.

\section{Las empresas de participación}

El 90\% de los estudiantes de la muestra manifiesta conocer que su centro docente es una sociedad cooperativa de enseñanza. De hecho, la mayoría de los estudiantes considera, que el hecho de que su centro docente sea una sociedad cooperativa, promueve en mayor medida la creación de sociedades cooperativas que otros centros educativos. No obstante, hay un porcentaje elevado (36\%) que no tiene una opinión formada al respecto.

El 59\% de los estudiantes manifiesta conocer los Principios Cooperativos de la Alianza Cooperativa Internacional frente al $41 \%$ restante. Un $44 \%$ de los estudiantes considera que dichos principios reflejan de forma regular la educación recibida en el colegio, un $25 \%$ considera que bastante frente a un $23 \%$ que cree que muy poco o nada. Los resultados no son tan satisfactorios como esperábamos. Asimismo, el 53\% de los estudiantes contesta que no sabe lo que es la economía social.

Aunque la mayoría de los estudiantes considera que las sociedades laborales, sociedades cooperativas y trabajadores autónomos son empresas, no hay que despreciar el porcentaje que considera que no lo son, un $36 \%$ en el caso de la sociedad laboral, un $29 \%$ en la sociedad cooperativa y un $41 \%$ en el trabajador autónomo. Entendemos que estas diferencias pueden deberse al desconocimiento de las formas jurídicas 
de sociedad laboral y trabajador autónomo. Llama la atención que, al 27\% de los estudiantes les es indiferente la forma jurídica, si en el futuro tomasen la decisión de crear una empresa. Un $24 \%$ preferiría ser empresario individual o profesional independiente, un $18 \%$ una sociedad cooperativa y un porcentaje elevado (23\%) no lo sabe.

\section{La valoración y evaluación con respecto a los conocimientos adquiridos}

La inmensa mayoría de los estudiantes no conoce experiencias de creación de empresas por antiguos alumnos de su colegio. El $43 \%$ de los estudiantes consideran que cursar la asignatura de Iniciativa Emprendedora les ha permitido adquirir capacidades empresariales generales como la creatividad, innovación, curiosidad, trabajar en equipo, confianza en sí mismo, liderazgo, capacidad de asumir riesgos; un $33 \%$ considera que han mejorado en capacidades empresariales específicas como el conocimiento para poner en marcha una empresa: elaboración de un plan de negocio; la capacidad de detectar oportunidades, el conocimiento de las finanzas, etc.; y un $25 \%$ cree que han adquirido conocimientos sobre los aspectos específicos de las empresas de participación y la economía social.

La mayoría de los alumnos manifiestan que sus profesores nunca les han preguntado por sus profesores respecto a sus preferencias de futuro como empresario o trabajador por cuenta ajena. Mientras que un $22 \%$ reconoce que les han preguntado antes y después de cursar la asignatura de Iniciativa Emprendedora, otro $11 \%$ sostiene que les han consultado antes de cursarla, y un $9 \%$ dice que después de haberla cursado. Parece constatarse un efecto positivo después de cursar la asignatura Iniciativa Emprendedora, puesto que, el 29\% de los estudiantes manifiesta que con un mayor conocimiento de la creación de empresas, después de haberla cursado, lo contempló como una salida profesional; mientras que un $22 \%$ dice que nunca se lo ha planteado, ni antes ni después de cursarla; y otro $22 \%$ indica que estudió la asignatura de iniciativa emprendedora porque siempre tuvo en mente la posibilidad de crear una empresa.

El $86 \%$ de los estudiantes contesta que recomendaría a otros estudiantes cursar la asignatura de iniciativa emprendedora, porque, de hecho, el $28 \%$ considera que es importante cursarla para su futuro profesional, al $20 \%$ se la recomendaron otros alumnos, un $9 \%$ dice que se lo sugirió algún profesor, frente al 21\% que contesta que no tenía más remedio porque no tenía opción de elegir, y un 22\% considera que se aprueba fácil.

Finalmente, el $41 \%$ de los estudiantes cree que de modo regular la formación sobre emprendimiento que ha recibido sienta las bases para crear una empresa en el futuro, el 39\% considera que les ha ayudado bastante o mucho, frente al $20 \%$ que considera que muy poco o nada.

\section{La percepción del emprendimiento de participación por parte de los órganos de dirección de los centros de enseñanza}

Los cuestionarios dirigidos a los centros son contestados por los responsables de estos (directores) o por los coordinadores del ciclo correspondiente a la impartición de la asignatura de iniciativa emprendedora.

Se pone de manifiesto a continuación su percepción con respecto a los cinco bloques fundamentales del cuestionario.

\section{El emprendimiento y la creación de empresas}

Los directores y coordinadores de los centros entrevistados valoran muy positivamente las iniciativas que en materia emprendedora se les plantea realizar en su centro siendo la simulación de empresas con fines educativos la que obtiene una mayor puntuación. Las iniciativas de creación y gestión por parte de los alumnos de sus propias empresas así como la realización de jornadas y talleres de sensibilización para fomentar el espíritu emprendedor son las valoradas a continuación. La menor valoración la obtiene la iniciativa relacionada con las visitas de empresarios al aula que cuenten a los alumnos su propia experiencia.

La Ley de apoyo al Emprendedor, en su artículo 4, establece que los currícula de Educación Primaria, Secundaria Obligatoria, Bachillerato y Formación Profesional incorporarán objetivos, contenidos y competencias para la creación y desarrollo de los diversos modelos de empresas. En este orden de cosas, la opinión de los directores de los centros se concreta:

1. La valoración global de los objetivos en materia de cultura emprendedora obtiene una calificación de 4,35 sobre 5, valorándose en primer lugar, el entendimiento del concepto de espíritu emprendedor 
y la actitud emprendedora y conocer los recursos clave para crear una empresa o proyecto empresarial: financieros, humanos y de información y saber cuáles se necesitan en cada caso concreto, siendo el resto de los objetivos valorados muy positivamente.

2. Los contenidos relacionados con el emprendimiento obtienen como promedio una calificación de 3,96 sobre 5. Los recursos en el proceso emprendedor son los contenidos prioritarios que deben ser tenidos en cuenta por el colegio para formarlos en la cultura del emprendimiento; en segundo lugar, asume un gran protagonismo la creatividad; por último, se considera importante el conocimiento de los factores de éxito y de fracaso de los proyectos empresariales. Los responsables de los centros, valoran en menor medida, las actitudes hacia el emprendimiento y el estudio de las distintas formas jurídicas así como la formación específica en materia de sociedades cooperativas y laborales.

3. La valoración de competencias consigue una puntuación de 4,5 sobre 5 . Las competencias que en este caso son menos valoradas son las competencias sociales y de ciudadanía y las culturales y artísticas.

Se presenta a los directores y coordinadores un conjunto de actitudes relacionadas con el emprendimiento para su valoración en una escala del 0 al 10 . Las actitudes más valoradas son el liderazgo, el compromiso y la responsabilidad. La menos valorada es la juventud, seguida de la asunción de riesgos, la ambición y el carisma.

Se presentaron para su valoración un conjunto de factores que pudieran llegar a ser determinantes en la decisión de emprender. Es destacable conocer la opinión de los entrevistados sobre la correlación positiva entre la formación en materia de emprendimiento y el futuro de los alumnos como emprendedores. Por su parte, los entrevistados consideran que el estudio en materia de emprendimiento puede mejorar el desarrollo profesional de los alumnos e influirá en la decisión. Por el contrario, el factor que menos determinaría la decisión de emprender de los alumnos es el conocimiento de experiencias de éxito de emprendedores, provenir de una familia en la que exista algún emprendedor y la autorrealización personal.

Lo anterior contrasta con las ventajas que se consideran más importantes de ser emprendedor. La mejor valorada, la autorrealización o satisfacción personal. La menos valorada, la posibilidad de evitar la limitación de la carrera profesional por bloqueos en el ascenso laboral.

Los organos de dirección de los centros consideran que los inconvenientes de ser emprendedor se relacionan con la variabilidad de los ingresos, la asunción de riesgos y responsabilidades, la mayor jornada laboral, la incertidumbre y la dificultad de obtener recursos financieros.

El 75\% de los entrevistados considera que en su centro se difunden convenientemente entre los alumnos, los valores y las competencias personales y profesionales del emprendedor así como que se presta especial atención al espíritu empresarial y a la creación de empresas; por su parte, observan que en sus centros los alumnos manifiestan bastante interés en materia de emprendimiento y que se podría fomentar el emprendimiento invitando a ex alumnos del centro, que sean empresarios para contar su experiencia con el fin de que los alumnos puedan sentirse más identificados con ellos; del mismo modo, las visitas a empresas pueden contribuir a la difusión de la cultura emprendedora. La utilización de programas de simulación empresarial y la utilización de medios técnicos son las opciones menos valoradas.

Del conjunto de dificultades que se plantea a los entrevistados para promover el emprendimiento en el centro del que son responsables, se destaca la falta de fomación específica del profesorado en materias de creación de empresas.

\section{Los aspectos específicos de la asignatura de iniciativa emprendedora}

La asignatura de Iniciativa Emprendedora viene impartiéndose en los centros entrevistados desde hace más de cinco años. Los resultados de la puesta en marcha de la asignatura han sido valorados muy positivamente por contribuir a la motivación de los valores del emprendimiento entre el alumnado.

La totalidad de los entrevistados considera que la asignatura Iniciativa Emprendedora debe ser troncal u obligatoria. Se les pregunta si en la asignatura se promueven de forma específica la creación de sociedades cooperativas y sociedades laborales y todos ellos contestan positivamente.

Los responsables de los centros consideran mayoritariamente que el perfil del alumnado no es determinante a la hora de escoger la asignatura de Iniciativa Emprendedora si bien hay una creencia generalizada en la relación de la asignatura y el itinerario de ciencias sociales. 
Se les solicita a los encuestados una valoración de las actividades realizadas en la asignatura de Iniciativa Emprendedora. Las mejor valoradas son la participación de los alumnos de forma activa en el proceso de aprendizaje. Gracias a la asignatura se mejoran las capacidades de los estudiantes para trabajar en equipo, se resuelven problemas y se descubren oportunidades.

Por su parte, se promueve el desarrollo de actitudes relacionadas con el espíritu empresarial tales como la creatividad, la iniciativa, la asunción de riesgos, o la responsabilidad, entre otras.

Destaca la opinión mayoritaria de que en la asignatura de iniciativa emprendedora se explican los aspectos específicos de las empresas de participación y la economía social.

Los responsables de los centros entrevistados consideran que la principal ventaja de la simulación de proyectos empresariales es que los alumnos aprenden a trabajar en equipo y se incrementa su interés por el emprendimiento y la creación de empresas.

Por último en este bloque, hay coincidencia de todos los entrevistados en que los apoyos didácticos que el centro pone a disposición de los profesores en la asignatura de Iniciativa Emprendedora son el material didáctico de carácter lúdico y participativo para dar a conocer ejemplos de empresarios, y ayudar al alumno a familiarizarse con los conceptos asociados a un plan de empresa.

\section{Las empresas de participación}

En el bloque correspondiente a las empresas de participación se procura conocer cuáles son las medidas que deberían desarrollarse para generar una oferta formativa que procure el impulso a la creación de sociedades cooperativas y laborales entre su alumnado. En este orden de cosas, se considera que la mejor medida sería fomentar la aplicación práctica mediante el desarrollo de proyectos entre los propios alumnos (37,5\%); a continuación, considerar la asignatura como obligatoria (25\%) y establecer unos contenidos comunes en todo el Estado (25\%); por último, incidir en las bondades de las sociedades cooperativas y laborales (12,5\%).

La totalidad de los entrevistados considera que la forma jurídica del centro docente influye en la promoción del cooperativismo y de las otras empresas de participación y que se divulgan bastante los principios y valores del cooperativismo y la economía social en general entre su alumnado.
La totalidad de los responsables de los centros considera que los alumnos y sus padres conocen que su centro escolar es una cooperativa de enseñanza y el $75 \%$ piensa que la forma jurídica no influye en la elección del centro. No hay acuerdo en la consideración de si el centro trasmite o no su condición jurídica y los valores y principios cooperativos, y tampoco hay acuerdo sobre si los valores y principios cooperativos son transmitidos a los alumnos y a sus padres a través de las actividades que realiza.

\section{La valoración y evaluación con respecto a los conocimientos adquiridos}

El 50\% de los responsables de los centros considera que su centro no realiza un seguimiento de los proyectos empresariales que los alumnos han puesto en marcha cuando finalizan el proceso académico, mientras que el 50\% restante considera que sí se realiza un registro pero que este no es formal.

El 50\% de los entrevistados considera que los alumnos adquieren capacidades empresariales generales: creatividad, capacidad de proponer ideas innovadoras, curiosidad, capacidad de trabajar en equipo, confianza en sí mismo, liderazgo, capacidad de asumir riesgos, competencias para resolver problemas, responsabilidad, etc., al cursar la asignatura de Iniciativa Emprendedora; el 50\% restante considera que los alumnos reciben formación concreta sobre aspectos específicos de las empresas de participación y la economía social.

El 75\% de los responsables de los centros están de acuerdo en considerar que la imagen de las sociedades cooperativas mejora en la medida en que los alumnos disponen de mayor información y que la influencia de padres y familiares con respecto a la imagen de las sociedades cooperativas es muy importante. Además, los alumnos con una mayor propensión a la creación de empresas son aquellos que familiarmente tienen una vinculación mayor con las empresas. Del mismo modo, el 75\% considera que hay una correlación positiva entre la posibilidad de los alumnos de crear empresas y la formación recibida, y un $50 \%$ considera que el hecho de que dichas empresas sean sociedades cooperativas depende de la formación recibida.

\section{Formación y grado de involucración con el emprendimiento}

El 75\% de los entrevistados indica que las medidas que contribuyen a la formación permanente del 
profesorado son la realización de cursos específicos, y proyectos de colaboración con empresas reales.

Además, el 100\% de los responsables de centros opina que la enseñanza sobre emprendimiento y creación de empresas debe formar parte de los programas de formación inicial obligatoria del profesorado.

Las medidas para incrementar el grado de involucración de los profesores en temas relacionados con el emprendimiento y la creación de empresas que son más valoradas por los centros son:

- Contar con sistemas de apoyo tales como personal especializado a quien poder realizar consultas.

- Firmar acuerdos que permitan al profesorado adquirir experiencia empresarial mediante el establecimiento de estancias en empresas.

Se valora en menor medida la concesión de premios a los profesores comprometidos con la educación en emprendimiento y creación de empresas.

\section{La percepción del emprendimiento de participación por parte de los profesores que imparten la asignatura de Iniciativa Emprendedora}

\section{El emprendimiento y la creación de empresas}

La Iniciativa Emprendedora más valorada por los profesores es la organización de visitas de empresarios $(5,00$ sobre 5,00$)$, seguida de las visitas guiadas a empresas y viveros de empresas $(4,50$ sobre 5,00$)$, la elaboración de material didáctico de carácter lúdico y participativo $(4,33$ sobre 5,00$)$, la utilización de programas de simulación de empresas con fines educativos y la realización de jornadas y talleres de sensibilización $(4,00$ sobre 5,00$)$, la creación y gestión por parte de los alumnos de sus propias empresas $(3,67)$, y por último, la iniciativa que obtiene la menor puntuación media es la organización de concursos de ideas empresariales y organización de olimpiadas de emprendedores $(1,00$ sobre 5,00 ).

La Ley de Apoyo al Emprendedor en su artículo 4 establece que los currícula de Educación Primaria, Secundaria Obligatoria, Bachillerato y Formación Profesional incorporarán objetivos, contenidos, y competencias para la creación y desarrollo de los diversos modelos de empresa.

Los profesores otorgan la máxima puntuación media $(5,00$ sobre 5,00$)$ a los objetivos de conocer diversas alternativas y manifestaciones del fenómeno emprendedor y de aplicar la creatividad para encontrar una idea de negocio propia. No obstante, también consideran muy importantes, otorgándoles una valoración media de 4,75 (sobre 5,00), los objetivos de distinguir las diversas fases para poner en marcha un proyecto emprendedor y diferenciar y evaluar una idea de una oportunidad de negocio. Los siguientes objetivos en función de la puntuación media son el entender los conceptos de espíritu emprendedor y actitud emprendedora (4,50 sobre 5,00$)$, reconocer los rasgos de las personas emprendedoras y los factores clave de los equipos fundacionales de una nueva empresa $(4,25$ sobre 5,00$)$, conocer los recursos clave para crear una empresa/proyecto emprendedor $(4,25$ sobre 5,00$)$, conocer los modelos alternativos de emprendimiento que plantean las sociedades cooperativas y otras empresas de participación $(4,25$ sobre $5,00)$ y conocer las principales características de las nuevas empresas en la actualidad $(3,75$ sobre 5,00$)$.

El objetivo que es considerado menos importante, y por tanto, obtiene la menor puntuación media $(3,50$ sobre 5,00$)$, es el reconocer la utilidad de un plan de empresa, su estructura y contenidos.

En lo relativo a los contenidos, los profesores valoran que el contenido más importante, y por tanto, al que le otorgan la máxima puntuación de 5,00 sobre 5,00, es la idea de negocio a la oportunidad, y al papel de la creatividad.

No obstante, también son considerados muy importantes con una puntuación de 4,50 sobre 5,00 , los contenidos que hacen referencia al espíritu emprendedor y las actitudes hacia la actividad emprendedora y los recursos en el proceso emprendedor. Los contenidos relacionados con el estudio de las sociedades cooperativas y otras empresas de participación como fórmulas para emprender y los factores de éxito y de fracaso de los nuevos proyectos empresariales obtienen una puntuación de 4,00 sobre 5,00 , seguidos de los contenidos sobre el emprendedor como protagonista de la actividad emprendedora y el plan de empresa $(3,75$ sobre 5,00$)$. Por último, los contenidos sobre el estudio de las diversas formas jurídicas para emprender son los menos valorados con una puntuación media de 3,5 sobre 5,00 .

Por lo que se refiere a las competencias, los profesores consideran más importantes, y por tanto, les otorgan la máxima puntuación $(5,00$ sobre 5,00$)$, a las relativas al conocimiento y a la interacción con el mundo físico, la competencia social y ciudadana, la competencia para aprender a aprender y la autonomía 
e iniciativa personal. Las siguientes competencias mejor valoradas por parte de los profesores (4,75 sobre $5,00)$ son la competencia en comunicación lingüística y el tratamiento de la información y competencia digital. Las competencias que obtienen la menor valoración son la matemática y la cultural y artística $(4,50$ sobre 5,00$)$.

Las actitudes relacionadas con el emprendimiento que son consideradas más importantes por parte de los profesores, y que por ello obtienen la máxima valoración $(10,00$ sobre 10,00$)$ son la responsabilidad y la motivación. Además, los profesores otorgan una puntuación media superior a 9,00 (sobre $10,00)$ a las actitudes de iniciativa, capacidad creativa e innovadora, compromiso, compañerismo y asunción de compromisos.

Cabe destacar que los profesores no consideran que la juventud esté relacionada con el emprendimiento, obteniendo así una puntuación media de 3,25 (sobre 10,00).

Las actitudes propuestas, a excepción del carisma $(7,50$ sobre 10,00$)$ y la juventud $(3,25$ sobre 10,00$)$, obtienen puntuaciones medias superiores a 8,00 sobre 10,00, por lo que los profesores consideran que están muy relacionadas con el emprendimiento.

Los factores que los profesores consideran más importantes en la decisión de ser emprendedor son el hecho de poder tener mejores posibilidades de desarrollo de la carrera profesional $(4,50$ sobre 5,00$)$, disponer de formación en materia de emprendimiento $(4,25$ sobre 5,00$)$, la existencia de un entorno fiscal y financiero favorable $(4,25$ sobre 5,00$)$ y la dificultad de encontrar trabajo como trabajador asalariado $(4,25$ sobre 5,00$)$. El factor que los profesores valoran en menor medida es el conocimiento de empresarios con éxito (3,00 sobre 5,00$)$.

Las ventajas más importantes de ser emprendedores según los profesores son la satisfacción personal (autorrealización) $(4,75$ sobre 5,00$)$, la independencia, la libertad de decisión y el control del negocio $(4,50$ sobre 5,00 ), así como la posibilidad de tener un trabajo ante la escasa oferta de empleo por cuenta ajena $(4,50$ sobre 5,00$)$.

Son valoradas con un 4,00 sobre 5,00 la flexibilidad en la organización y prestación del trabajo y la posibilidad de no ver limitada la carrera profesional por bloqueos en el ascenso laboral, mientras que la posibilidad de obtener mayores ingresos que como trabajador asalariado y el prestigio social, obtienen la menor valoración, 3,50 sobre 5,00 .
El mayor inconveniente que consideran los profesores a la hora de ser emprendedor es la incertidumbre sobre las perspectivas de crecimiento y consolidación de la empresa (4,50 sobre 5,00$)$, seguido de la variabilidad de ingresos $(4,25$ sobre 5,00$)$, la asunción de riesgo y la responsabilidad del negocio $(4,00$ sobre 5,00$)$, el tener que dedicar más horas a la empresa que siendo trabajador asalariado (4,00 sobre $5,00)$ y la dificultad de consecución de recursos financieros $(4,00$ sobre 5,00$)$.

Los profesores están de acuerdo con considerar que se difunde entre los alumnos los valores y las competencias personales y profesionales del emprendedor y consideran que el interés mostrado por los alumnos por la creación de empresas es regular (75\%), o bastante (25\%).

Para incrementar el interés de los alumnos en temas relacionados con la creación de empresas los profesores señalan que podrían llevarse a cabo iniciativas tales como la invitación a expertos externos, y profesionales del mundo empresarial, a las aulas que cuenten su experiencia como emprendedores, y hacer que los alumnos creen y gestionen sus propias empresas (100\% de los casos), la invitación a ex alumnos del centro, que sean empresarios, que cuenten su experiencia para que los alumnos puedan sentirse más identificados con ellos (75\%), la realización de visitas guiadas a empresas, la utilización de programas de simulación de empresas, y la utilización de métodos educativos fundamentalmente prácticos, dando menos peso a la explicación de contenidos teóricos (50\%).

Los profesores señalan como principales dificultades en su centro para implantar medidas que ayuden a los alumnos a interesarse por temas relacionados con la creación de empresas el no encontrar profesionales del mundo empresarial que colaboren de forma voluntaria (75\%), y la falta de formación específica del profesorado en temas de creación de empresas $(25 \%)$.

El $50 \%$ de los profesores considera que se dedica bastante atención al espíritu empresarial y a la creación de empresas, mientras que hay otro $50 \%$ que considera que se le dedica muy poca atención.

\section{Los aspectos específicos de la asignatura Iniciativa Emprendedora}

En todos los centros consultados, la asignatura Iniciativa Emprendedora lleva impartiéndose más de cinco años. El 50\% de los profesores considera bastante 
positivos los resultados de la puesta en marcha de esta asignatura en cuanto a la motivación entre el alumnado por medio de los valores del emprendimiento, mientras que otro $50 \%$ lo califica solo de regulares.

Los profesores están de acuerdo en considerar que sería deseable que las asignaturas de emprendimiento pasaran a conformar la oferta educativa troncal y obligatoria. Afirman que en sus centros se simula la creación de empresas, pero que en ninguno de ellos se promueve en absoluto la forma específica la creación de sociedades cooperativas y sociedades laborales.

Los profesores señalan que los alumnos que cursan esta asignatura son tanto de ciencias y tecnología como de ciencias sociales y humanidades, y opinan mayoritariamente que el programa de la asignatura tiene objetivos bien definidos, esta es fundamentalmente práctica y se basa en el trabajo en un proyecto empresarial, los estudiantes participan activamente en el proceso de aprendizaje, ponen en marcha y gestionan sus propias iniciativas, se mejoran las capacidades de los estudiantes para trabajar en equipo, resolver problemas y descubrir oportunidades, los contenidos de la asignatura permiten el desarrollo de competencias de comercialziación, gestión y dirección aplicadas a casos prácticos, se promueve el desarrollo de actitudes relacionadas con el espíritu empresarial tales como la creatividad, la iniciativa, la asunción de riesgos, o la responsabilidad, entre otras, se transmite al alumnado la cultura y los valores relacionados con el emprendimiento, y se explican los aspectos específicos de las empresas de participación y la economía social.

Por otra parte, la mayoría de los profesores también afirma, que los estudiantes no utilizan un simulador empresarial, no se realizan visitas guiadas a empresas, no se realizan concursos para premiar a los mejores proyectos empresariales, y que esta asignatura no forma parte de un programa más amplio de apoyo al emprendimiento.

Los profesores coinciden en señalar que las ventajas que tienen los alumnos por participar en procesos de creación de empresas son el hecho de que les permite aprender a trabajar en equipo, les permite mostrar su capacidad creativa e innovadora, aprenden a tomar decisiones, se responsabilizan de sacar adelante un proyecto empresarial, y se incrementa el interés de los alumnos por el emprendimiento y la creación de empresas.

El 75\% de los profesores indican que los apoyos didácticos que el centro pone a su disposición para impartir la asignatura de iniciativa emprendedora son material didáctico de carácter lúdico y participativo, para dar a conocer ejemplos de empresarios, y ayudar al alumno a familiarizarse con los conceptos asociados a un plan de empresa, y casos prácticos sobre experiencias reales, y el 25\%, mencionan el simulador empresarial.

Los profesores valoran que el interés por la asignatura es bajo, no la consideran fundamental, y los alumnos la escogen como alternativa para no cursar otras asignaturas, como por ejemplo Francés, al considerar que es una asignatura fácil de aprobar.

\section{Las empresas de participación}

Los profesores están de acuerdo en considerar como medidas que deberían desarrollarse para generar una oferta formativa que procure el impulso a la creación de sociedades cooperativas y laborales entre el alumnado, la consideración de la asignatura como obligatoria, y el fomento de la aplicación práctica mediante el desarrollo de proyectos entre los propios alumnos. Además, el 50\% de los profesores también valoran el hecho de incidir en las bondades de las sociedades cooperativas y laborales, y el establecimiento de unos contenidos comunes en todo el Estado.

Por otra parte, los profesores consideran que la forma jurídica del centro influye en la promoción del cooperativismo y en otras empresas de participación. Sin embargo, solo el $50 \%$ valora que se divulguen bastante los principios y valores del cooperativismo y la economía social en general entre sus alumnos, mientras que el $25 \%$ lo califica como mucho, y otro $25 \%$ como regular.

Los profesores valoran con 4,50 sobre 5,00 , - por tanto, están de acuerdo- que los valores y principios cooperativos son transmitidos a los alumnos y a sus padres a través de las actividades que realiza el centro docente cooperativo. Además, consideran que el centro transmite a padres y alumnos la condición jurídica del centro educativo y sus valores y principios (3,67 sobre 5,00 ) y que los alumnos y sus padres conocen que su centro es una sociedad cooperativa pero que eso no influye en el momento de su elección (3,50 sobre 5,00$)$.

Con la afirmación que están menos de acuerdo es con la de que los alumnos y sus padres desconocen que su centro escolar es una sociedad cooperativa $(2,25$ sobre 5,00$)$.

\section{La valoración y evaluación con respecto a los conocimientos adquiridos}

El 75\% de los profesores considera que su centro no realiza un seguimiento de los proyectos empresariales 
que los alumnos han puesto en marcha cuando finalizan el proceso académico, mientras que un $25 \%$, indica que sí, aunque no formalmente.

Los profesores consideran que los alumnos, con la formación recibida, han adquirido competencias empresariales generales (100\%), capacidades empresariales específicas (50\%), y conocimientos sobre los aspectos específicos de las empresas de participación y la economía social (50\%).

Los profesores están bastante de acuerdo al considerar que la imagen de las sociedades cooperativas mejora en la medida que los alumnos disponen de mayor información $(4,25$ sobre 5,00$)$, que la influencia de padres y familiares con respecto a la imagen de las sociedades cooperativas es muy importante $(4,00$ sobre 5,00$)$ y que los alumnos con una mayor propensión a la creación de empresas son aquellos que familiarmente tienen una vinculación mayor con estas (padres o familiares empresarios); $(4,00$ sobre 5,00$)$.

Las afirmaciones que obtienen las menores puntuaciones $(3,5$ sobre 5,00$)$ son las que consideran que hay una correlación positiva entre la posibilidad de los alumnos de crear empresas (considerando también la posibilidad de que sean sociedades cooperativas) y la formación recibida.

\section{Formación y grado de involucración con el emprendimiento}

El 50\% de los profesores considera que las medidas que contribuyen a la formación permanente del profesorado son la realización de cursos específicos, mientras que el $25 \%$ valora la realización de jornadas profesionales del mundo empresarial, y los proyectos de colaboración con empresas reales.

Además, el 75\% de los profesores, opina que la enseñanza sobre emprendimiento y creación de empresas debería formar parte de los programas de formación inicial obligatoria del profesorado.

Las medidas que los profesores consideran más importantes para incrementar su grado de involucración en temas relacionados con el emprendimiento y la creación de empresas son tener acceso a un centro de conocimientos virtual que permita compartir material didáctico, metodologías docentes, programas, actividades complementarias, experiencias de otros profesores, casos de buenas prácticas $(4,75$ sobre 5,00$)$ y contar con sistemas de apoyo, tales como personal especializado a quien poder realizar consultas $(4,50$ sobre 5,00 ).
También consideran importantes, aunque en menor medida, la firma de acuerdos por parte de los centros que permitan al profesorado adquirir experiencia empresarial mediante el establecimiento de estancias en empresas $(4,33$ sobre 5,00$)$ y realizar encuentros presenciales entre los profesores que imparten asignaturas relacionadas con el emprendimiento, y la creación de empresas, de distintos centros con el objetivo de intercambiar experiencias $(4,25$ sobre $5,00)$.

La medida menor valorada es la concesión de premios a los profesores comprometidos con la educación en emprendimiento y creación de empresas $(3,00$ sobre 5,00$)$.

\section{Conclusiones}

Los jóvenes son uno de los colectivos más afectados por el desempleo, la temporalidad de los contratos, y las jornadas a tiempo parcial, por lo que, ante la dificultad de encontrar empleo por cuenta ajena, el emprendimiento puede suponer una alternativa al trabajo asalariado que les permita tanto incorporarse, como mantenerse en el mercado laboral, y mejorar sus condiciones de trabajo.

No cabe duda de que el emprendimiento constituye la base del crecimiento económico, y es ahí donde las empresas de participación pueden desempeñar un papel clave en la recuperación económica de nuestro país.

Las empresas de participación son formas de empresas que contribuyen al desarrollo territorial, en las que es inherente a su condición una especial sensibilidad en términos de responsabilidad social, que no se deslocalizan y que permiten así una mayor integración y cohesión social aportando al mismo tiempo riqueza y empleo de calidad y estable allí donde se encuentran. Es por ello que también son fórmulas adecuadas para dar respuesta a los retos del cambio demográfico, como pueden ser el relevo generacional, la igualdad efectiva de la mujer, o la incorporación de la población inmigrante al mercado laboral.

Con todo, los jóvenes españoles, afectados por una elevadísima tasa de desempleo, siguen mostrando una escasa vocación emprendedora si bien, no obstante, se está procurando en todos los ámbitos educativos incorporar competencias en materia de emprendimiento lo que conformará una mayor cultura emprendedora que redundará, sin ninguna duda, en una mayor creación de riqueza por parte de los jóvenes a través de la creación de empresas. 
En el ámbito particular de las empresas de participación, es necesario promover ya no solo la cultura de emprender bajo estas formas jurídicas sino un impulso en materia de formación de profesores y prescriptores.

Evidentemente, es precisa una coordinación de las materias y competencias en todos los niveles educativos de modo que en la universidad, las oficinas técnicas universitarias de apoyo en materia de emprendimiento y el profesorado puedan jugar un papel determinante, promoviendo y difundiendo la cultura emprendedora y acompañando a los emprendedores en las fases iniciales de sus proyectos, prestándoles asesoramiento y formación.

En aras de promover la coordinación necesaria se concluye la necesidad de:

1. Incentivar la creación empresarial desde los niveles inferiores de enseñanza.

2. Promover asignaturas relacionadas no solo con emprendimiento en general sino con emprender bajo fórmulas de participación en particular.

3. Informar de las posibles alternativas que ofrece el emprendimiento en general.

4. Recalcar las ventajas y el potencial de las empresas de participación.

5. Estudiar de manera concreta los problemas a los que se enfrentan los trabajadores de las empresas de participación en la actualidad para poder formar a los potenciales emprendedores con base en el optimismo y las oportunidades que ofrece esta vía de emprendimiento a través de herramientas concretas de apoyo.

6. Incentivar a que las sociedades cooperativas, fundamentalmente en el ámbito educativo, promuevan la creación de sociedades cooperativas.

7. Apoyar las iniciativas en cualquiera de los niveles educativos y, por supuesto, en las universidades que se vienen desarrollando para promover el espíritu emprendedor para lo cual es necesario reforzar la formación de técnicos encargados de las labores de asesoramiento y formación en las particularidades de algunas fórmulas empresariales, en particular, las empresas de participación (tanto sociedades cooperativas, como sociedades laborales y empresas individuales -trabajo autónomo) para que estas fórmulas sean tenidas en cuenta y no se derive en otras estructuras basándose en tópicos que se alejan de la realidad por desconocimiento de aspectos muy concretos que les atañen.
Hay motivos para pensar en una nueva generación de emprendedores capaces de crear empresas que superen las dificultades existentes y, sobre todo, que proporcione a los jóvenes, desde tempranas edades, una alternativa y una esperanza en la contribución a la generación de riqueza, personal y social, y que además, cobren importancia aquellas empresas que procuran el protagonismo de estos jóvenes en todos los aspectos, esto es, las empresas de participación.

Las principales conclusiones de este estudio se observan en los distintos colectivos y se sintetizan en las tablas 1-5.

Se presentan las conclusiones generales del estudio:

1. La valoración de la puesta en marcha en los centros de programas de emprendimiento y creación de empresas se valora como positiva.

2. No existe unanimidad en la valoración de los objetivos y contenidos en materia emprendedora pero todos ellos son tendentes a desarrollar y buscar programas que promuevan el espíritu emprendedor y la creatividad.

3. El liderazgo y la responsabilidad son las actitudes del emprendimiento mejor valoradas por los profesores y los centros no tanto por los alumnos que destacan la innovación y la capacidad creativa. Hay unanimidad en todos los colectivos al resaltar que la actitud menos importante para el emprendimiento es la juventud.

4. La autorrealización y la satisfacción personal son las ventajas más valoradas por los responsables de los centros y profesores mientras que los alumnos valoran en mayor medida la independencia y la libertad de decisión. Sin embargo, todos los colectivos coinciden en destacar la incertidumbre como el principal inconveniente.

5. No hay unanimidad en la percepción que unos y otros hacen de la valoración de los alumnos por el emprendimiento; es destacable que los alumnos lo califican de regular lo que, sin duda, ha de hacernos reflexionar sobre en qué nos estamos equivocando para que nuestro mensaje no les llegue, ya que todos los entrevistados están de acuerdo en afirmar que sí hay transmisión de valores y competencias del emmprendedor entre los alumnos.

6. La respuesta es unánime cuando se les pregunta por las medidas para incentivar el interés en materia de iniciativa emprendedora: la invitación a expertos y a antiguos alumnos que cuenten sus experiencias. La dificultad encontrada por los 
Tabla 1

Conclusiones emprendimiento

\begin{tabular}{|c|c|c|c|}
\hline Cuestiones fundamentales & Centros & Profesores & Alumnos \\
\hline Valoración general & Positiva & Positiva & Positiva \\
\hline Iniciativas más valoradas & $\begin{array}{c}\text { Simulación de empresas con fines } \\
\text { educativos }\end{array}$ & Visitas de empresarios al aula & $\begin{array}{l}\text { Simulación de empresas con } \\
\text { fines educativos }\end{array}$ \\
\hline Valoración de los objetivos & $\begin{array}{l}\text { Entendimiento del concepto del } \\
\text { espíritu emprendedor y la actitud } \\
\text { emprendedora }\end{array}$ & $\begin{array}{l}\text { Conocimiento de alternativas y } \\
\text { manifestaciones del fenómeno } \\
\text { emprendedor }\end{array}$ & $\begin{array}{c}\text { Aplicar la creatividad para } \\
\text { encontrar una idea de negocio } \\
\text { propia }\end{array}$ \\
\hline Valoración de contenidos & $\begin{array}{l}\text { Los recursos en el proceso } \\
\text { emprendedor }\end{array}$ & El papel de la creatividad & $\begin{array}{c}\text { El espíritu emprendedor y las } \\
\text { actitudes hacia la actividad } \\
\text { emprendedora }\end{array}$ \\
\hline \multirow{3}{*}{ Las actitudes mejor valoradas } & Responsabilidad & Responsabilidad & Capacidad creativa \\
\hline & Compromiso & Motivación & Innovación \\
\hline & Liderazgo & Liderazgo & \\
\hline Las actitudes peor valoradas & Juventud & Juventud & Juventud \\
\hline $\begin{array}{l}\text { Factores que determinan la } \\
\text { decisión de emprender }\end{array}$ & La formación. & $\begin{array}{l}\text { La formación } \\
\text { Mejores posibilidades de desa- } \\
\text { rrollo de la carrera profesional. }\end{array}$ & $\begin{array}{l}\text { Mejores posibilidades de desa- } \\
\text { rrollo de la carrera profesional. }\end{array}$ \\
\hline Ventajas emprendedor & $\begin{array}{l}\text { Autorrealización o satisfacción } \\
\text { personal }\end{array}$ & $\begin{array}{l}\text { Autorrealización o satisfacción } \\
\text { personal }\end{array}$ & $\begin{array}{l}\text { Independencia y libertad de } \\
\text { decisión }\end{array}$ \\
\hline \multirow[b]{2}{*}{ Inconvenientes emprendedor } & Incertidumbre & Incertidumbre & Incertidumbre \\
\hline & Variabilidad de ingresos. & Variabilidad de ingresos. & $\begin{array}{l}\text { Dificultades de obtener recur- } \\
\text { sos financieros. }\end{array}$ \\
\hline Interés de los alumnos & Bastante & Regular & Regular \\
\hline $\begin{array}{l}\text { Difusión entre los alumnos } \\
\text { los valores y las competen- } \\
\text { cias del emprendedor }\end{array}$ & Sí & Sí & Sí \\
\hline $\begin{array}{l}\text { Medidas para incentivar el } \\
\text { interés en materia de inicia- } \\
\text { tiva emprendedora }\end{array}$ & $\begin{array}{l}\text { La invitación a ex alumnos del } \\
\text { centro y a expertos que sean } \\
\text { empresarios para que cuenten su } \\
\text { experiencia a los alumno }\end{array}$ & $\begin{array}{l}\text { La invitación a ex alumnos del } \\
\text { centro y a expertos que sean } \\
\text { empresarios para que cuenten } \\
\text { su experiencia a los alumno }\end{array}$ & $\begin{array}{l}\text { La invitación a ex alumnos del } \\
\text { centro y a expertos que sean } \\
\text { empresarios para que cuenten } \\
\text { su experiencia a los alumno }\end{array}$ \\
\hline \multirow{2}{*}{$\begin{array}{l}\text { Dificultades para implantar } \\
\text { las medidas }\end{array}$} & \multirow[t]{2}{*}{ Falta de formación } & Falta de formación & \\
\hline & & No encontrar profesionales & \\
\hline $\begin{array}{l}\text { Atención al espíritu empren- } \\
\text { dedor }\end{array}$ & Mucho & Regular & Poco \\
\hline $\begin{array}{l}\text { Enseñanza sobre emprendi- } \\
\text { miento }\end{array}$ & Primaria y/o secundaria & Primaria y/o secundaria & Primaria y/o secundaria \\
\hline
\end{tabular}

Nota. Elaboración propia. 
Tabla 2

Asignatura de iniciativa emprendedora

\begin{tabular}{|c|c|c|c|}
\hline Cuestiones fundamentales & Centros & Profesores & Alumnos \\
\hline Valoración & Muy positiva & Positiva & Positiva \\
\hline Troncal/obligatoria u optativa & Troncal u obligatoria & Troncal u obligatoria & Optativa \\
\hline Simulación de empresas & Sí & Sí & Sí \\
\hline $\begin{array}{l}\text { Promoción de empresas de } \\
\text { participación }\end{array}$ & Mucho & Bastante & Regular \\
\hline Perfil de alumnos & No determinante & No determinante & No determinante \\
\hline \multirow{4}{*}{ Valoración de las actividades } & $\begin{array}{l}\text { Los alumnos ponen en marcha y } \\
\text { gestionan sus propias iniciativas } \\
\text { empresariales }\end{array}$ & $\begin{array}{l}\text { Los alumnos ponen en marcha y } \\
\text { gestionan sus propias iniciativas } \\
\text { empresariales }\end{array}$ & $\begin{array}{l}\text { Los alumnos ponen en marcha } \\
\text { y gestionan sus propias inicia- } \\
\text { tivas empresariales }\end{array}$ \\
\hline & $\begin{array}{l}\text { Se explican asuntos específicos } \\
\text { de las empresas de participación }\end{array}$ & $\begin{array}{l}\text { Se explican asuntos específicos } \\
\text { de las empresas de participación }\end{array}$ & $\begin{array}{l}\text { No hay unanimidad al refe- } \\
\text { rirse a la promoción de las } \\
\text { empresas de participación }\end{array}$ \\
\hline & $\begin{array}{l}\text { No se utilizan simuladores de } \\
\text { empresas }\end{array}$ & $\begin{array}{l}\text { No se utilizan simuladores de } \\
\text { empresas }\end{array}$ & $\begin{array}{c}\text { No se utilizan simuladores de } \\
\text { empresas }\end{array}$ \\
\hline & $\begin{array}{l}\text { No cuentan con la experiencia } \\
\text { de emprendedores }\end{array}$ & $\begin{array}{c}\text { No cuentan con la experiencia } \\
\text { de emprendedores }\end{array}$ & $\begin{array}{c}\text { No cuentan con la experiencia } \\
\text { de emprendedores }\end{array}$ \\
\hline Seguimiento de los alumnos & No & No & No \\
\hline \multirow{3}{*}{ Ventajas simulación empresas } & Trabajo en equipo & Trabajo en equipo & Trabajo en equipo \\
\hline & $\begin{array}{l}\text { Interés y conocimiento en la } \\
\text { creación de empresas }\end{array}$ & Interés emprendimiento & $\begin{array}{c}\text { Aumentar su capacidad crea- } \\
\text { tiva e innovadora }\end{array}$ \\
\hline & & & $\begin{array}{c}\text { Tomar decisiones y responsa- } \\
\text { bilizarse }\end{array}$ \\
\hline
\end{tabular}

Nota. Elaboración propia.

Tabla 3

Empresas de participación

\begin{tabular}{lccc}
\hline Cuestiones fundamentales & Centros & Profesores & Alumnos \\
\hline $\begin{array}{l}\text { Medidas para impulsar la } \\
\begin{array}{l}\text { creación de empresas de parti- } \\
\text { cipación }\end{array}\end{array}$ & $\begin{array}{c}\text { Simular su creación } \\
\text { Asignatura obligatoria }\end{array}$ & Asignatura obligatoria & Sí creación \\
\hline $\begin{array}{l}\text { Influencia de la forma jurídica } \\
\text { del centro }\end{array}$ & Sí & Sí & Sí \\
\hline $\begin{array}{l}\text { Conocimiento de los alumnos } \\
\text { y sus padres de la forma jurí- } \\
\text { dica del centro }\end{array}$ & Sí & No & No \\
\hline $\begin{array}{l}\text { Influencia en su decisión } \\
\begin{array}{l}\text { Valores y bondades de las } \\
\text { empresas de participación }\end{array}\end{array}$ & No & Sí & Regular \\
\hline
\end{tabular}

Nota. Elaboración propia. 
Tabla 4

Valoración y evaluación de los conocimientos adquiridos

\begin{tabular}{|c|c|c|c|}
\hline Cuestiones fundamentales & Centros & Profesores & Alumnos \\
\hline Seguimiento & No hay unanimidad & No se realiza & No lo conocen \\
\hline $\begin{array}{l}\text { Conocimiento del futuro } \\
\text { de los alumnos }\end{array}$ & No & No & No \\
\hline \multirow{3}{*}{$\begin{array}{l}\text { Adquisición de conoci- } \\
\text { mientos y capacidades }\end{array}$} & $\begin{array}{l}\text { Se adquieren capacidades } \\
\text { generales }\end{array}$ & $\begin{array}{l}\text { Se adquieren capacidades } \\
\text { generales }\end{array}$ & $\begin{array}{l}\text { Se adquieren capacidades } \\
\text { generales }\end{array}$ \\
\hline & $\begin{array}{l}\text { Se adquieren conocimientos } \\
\text { concretos sobre empresas de par- } \\
\text { ticipación en menor medida }\end{array}$ & $\begin{array}{l}\text { Se adquieren conocimientos } \\
\text { concretos sobre empresas de par- } \\
\text { ticipación en menor medida }\end{array}$ & $\begin{array}{l}\text { Se adquieren conocimientos } \\
\text { concretos sobre empresas de par- } \\
\text { ticipación en menor medida }\end{array}$ \\
\hline & $\begin{array}{l}\text { No se adquieren capacidades } \\
\text { específicas }\end{array}$ & $\begin{array}{l}\text { Se adquieren capacidades } \\
\text { específicas }\end{array}$ & $\begin{array}{l}\text { Se adquieren capacidades } \\
\text { específicas }\end{array}$ \\
\hline \multirow{4}{*}{ Valoración } & $\begin{array}{l}\text { La imagen que los alumnos tie- } \\
\text { nen de las empresas de participa- } \\
\text { ción mejora con la información } \\
\text { y formación }\end{array}$ & $\begin{array}{l}\text { La imagen que los alumnos tie- } \\
\text { nen de las empresas de participa- } \\
\text { ción mejora con la información } \\
\text { y formación }\end{array}$ & $\begin{array}{l}\text { La imagen que los alumnos tie- } \\
\text { nen de las empresas de participa- } \\
\text { ción mejora con la información } \\
\text { y formación }\end{array}$ \\
\hline & $\begin{array}{l}\text { La influencia de los padres con } \\
\text { respecto a la imagen sobre empre- } \\
\text { sas de participación es absoluta }\end{array}$ & $\begin{array}{l}\text { La influencia de los padres con } \\
\text { respecto a la imagen sobre empre- } \\
\text { sas de participación es absoluta }\end{array}$ & $\begin{array}{l}\text { La influencia de los padres con } \\
\text { respecto a la imagen sobre empre- } \\
\text { sas de participación es absoluta }\end{array}$ \\
\hline & $\begin{array}{l}\text { Los alumnos que en su entorno } \\
\text { familiar hay empresarios tienen } \\
\text { una mayor predisposición al } \\
\text { emprendimiento }\end{array}$ & $\begin{array}{l}\text { Los alumnos que en su entorno } \\
\text { familiar hay empresarios tienen } \\
\text { una mayor predisposición al } \\
\text { emprendimiento }\end{array}$ & $\begin{array}{l}\text { Los alumnos que en su entorno } \\
\text { familiar hay empresarios tienen } \\
\text { una mayor predisposición al } \\
\text { emprendimiento }\end{array}$ \\
\hline & $\begin{array}{l}\text { No se confía en la correlación } \\
\text { formación y creación }\end{array}$ & $\begin{array}{l}\text { No se confía en la correlación } \\
\text { formación y creación }\end{array}$ & $\begin{array}{l}\text { Si se confía en la correlación } \\
\text { formación y creación }\end{array}$ \\
\hline
\end{tabular}

Nota. Elaboración propia.

Tabla 5

Grado de involucración

\begin{tabular}{|c|c|c|}
\hline Cuestiones fundamentales & Centros & Profesores \\
\hline \multirow{3}{*}{ Formación de profesorado } & Cursos específicos & Cursos específicos \\
\hline & \multirow[t]{2}{*}{ Proyectos de colaboración con empresas reales } & Proyectos de colaboración con empresas reales \\
\hline & & Jornadas profesionales \\
\hline $\begin{array}{l}\text { Formación en emprendimiento } \\
\text { obligatoria para los profesores }\end{array}$ & Sí & Sí \\
\hline \multirow{5}{*}{$\begin{array}{l}\text { Medidas para incrementar el } \\
\text { grado de involucración }\end{array}$} & $\begin{array}{l}\text { Contar con personal especializado a quien } \\
\text { poder realizar consultas. Consultas a expertos }\end{array}$ & $\begin{array}{l}\text { Contar con personal especializado a quien } \\
\text { poder realizar consultas. Consultas a expertos }\end{array}$ \\
\hline & $\begin{array}{l}\text { Firmar acuerdos que permitan al profesorado } \\
\text { adquirir experiencia empresarial }\end{array}$ & Disponer de un simulador empresarial \\
\hline & $\begin{array}{l}\text { Realizar encuentros de los profesores de la asig- } \\
\text { natura de distintos centros para intercambiar } \\
\text { experiencias }\end{array}$ & Casos prácticos sobre experiencias \\
\hline & $\begin{array}{l}\text { Acceso a un centro de conocimientos virtual } \\
\text { que permita compartir material didáctico, } \\
\text { metodologías docentes, programas, actividades } \\
\text { complementarias }\end{array}$ & $\begin{array}{l}\text { Acceso a un centro de conocimientos virtual } \\
\text { que permita compartir material didáctico, } \\
\text { metodologías docentes, programas, actividades } \\
\text { complementarias }\end{array}$ \\
\hline & Concesión de premios a profesores & $\begin{array}{l}\text { Contar en el aula con material didáctico de } \\
\text { carácter lúdico y participativo, para dar a cono- } \\
\text { cer ejemplos de empresarios }\end{array}$ \\
\hline
\end{tabular}


responsables de los centros y los profesores para implementar las diferentes medidas es la falta de formación en esta materia.

7. Unanimidad, de igual modo, en proponer que las iniciativas en materia emprendedora han de ser desarrolladas desde educación primaria y continuar en secundaria y formación profesional.

8. Por lo que se refiere a la asgnatura de iniciativa emprendedora, de forma específica, la valoración es muy positiva por parte de todos los entrevistados.

9. Los responsables y profesores abogan por una asignatura que se imparta como troncal u obligatoria mientras que los alumnos consideran preferible que sea optativa; por su parte, el perfil de los alumnos (su itinerario) no es considerado determinante para cursar la asignatura.

10. La herramienta más valorada y más utilizada es la simulación de empresas; simulación en la que no parecen promoverse, al menos no hay consenso entre los entrevistados, las formas jurídicas de empresas de participación.

11. Se echan de menos, de forma unánime, dos herramientas de apoyo al emprendimiento en la asignatura de iniciativa emprendedora: Los simuladores de empresas, y las visitas de emprendedores que cuenten su experiencia.

12. Con respecto a las empresas de participación, en particular, la simulación de empresas bajo esta forma jurídica y la consideración de la asignatura como obligatoria redundaría en un mayor conocimiento y potenciación de la misma.

13. Se considera, de forma unánime, que la forma jurídica del centro en el que se imparte la asignatura influye en la decisión de la utilización de fórmulas participativas en la simulación de empresas, y es de esperar que también lo sea en el futuro emprendedor de los jóvenes alumnos. Por otro lado, los alumnos y sus padres conocen que su colegio es una sociedad cooperativa pero este factor no afecta la decisión de elegir el centro.

14. Los profesores y los centros afirman que se promueven los valores y principios cooperativos entre los alumnos mientras que estos no parecen percibirlo del mismo modo.

15. No se produce un seguimiento de los alumnos cuando finaliza el proceso académico por lo que no se tienen datos de su vida profesional y si esta se desarrolla por cuenta propia o ajena.

16. Al cursar la asignatura se adquiren conocimientos y capacidades generales; no se adquieren conocimientos específicos, como no puede ser de otra manera, al tratarse de una primera aproximación al ámbito del emprendimiento.

17. Tres consideraciones clave con respecto a la valoración de las empresas de participación:

- La imagen que los alumnos tienen de las empresas de participación mejora con la información y la formación.

- La influencia del entorno familiar es decisiva con respecto a la percepción que los alumnos tienen de las empresas de participación lo que podría condicionar, en un futuro, la elección de la forma jurídica de las empresas que pudieran desarrollar.

- La predisposición al emprendimiento es mayor en aquellos alumnos en los que en su entorno próximo hay empresarios.

18. Se destaca, de manera directa e indirecta, que la involucración de centros y profesorado en el emprendimiento pasa por una adecuada formación a través de cursos específicos, jormadas profesionales y proyectos de colaboración con universidades y empresas.

19. Además, se incorporan un conjunto de medidas que se tienen en consideración como propuestas de actuación.

\section{Propuestas de actuación}

Con base en las conclusiones que se obtienen del estudio, se establecen las siguientes propuestas relacionadas con cada uno de los bloques del estudio, así como propuestas generales.

\section{Propuestas relacionadas con el emprendimien- to y la creación de empresas}

- Potenciar la simulación de empresas con fines educativos fomentando la intercooperación con otras empresas ubicadas en otras regiones e incluso en otros países.

- Destacar, entre los contenidos que deben ser tenidos en cuenta por el colegio para formar a los alumnos en la cultura del emprendimiento, el espíritu emprendedor y las actitudes hacia la actividad emprendedora, el papel de la creatividad, y conocer los factores de éxito y de fracaso de los proyectos empresariales. Ponderar las ventajas frente a los inconvenientes de ser emprendedor conociendo bien ambos.

- Potenciar el interés de los alumnos en la creación de empresas desarrollando las medidas que 
han resultado ser más valoradas por los propios discentes como la realización de visitas guiadas a empresas; la invitación a expertos externos y profesionales del mundo empresarial a las aulas que cuenten su experiencia como emprendedores, y la utilización de programas de simulación de empresas.

- Potenciar la creación y gestión de sus propias empresas por parte de los alumnos para fomentar la cultura emprendedora en el colegio.

- Involucrar a padres y familiares emprendeedores para difundir las bondades del emprendimiento y las dificultades que conlleva, habida cuenta de la conocida correlación entre la actitud emprendedora de los alumnos y el entorno empresarial en el que se desenvuelven.

\section{Propuestas relacionadas con los aspectos espe- cíficos de la asignatura de iniciativa emprende- dora}

- Aumentar la dedicación a la enseñanza sobre el emprendimiento y creación de empresas en los programas de formación de los niveles educativos de primaria y secundaria planteando más asignaturas optativas relacionadas.

- Promover concursos para premiar los mejores proyectos empresariales como medida incentivadora.

- Promover que las asignaturas de emprendimiento pasen a conformar la oferta educativa troncal y obligatoria.

- Fomentar en mayor medida la utilización en los centros de materiales didácticos de carácter lúdico y participativo, para dar a conocer ejemplos de empresarios, y ayudar al alumnado a familiarizarse con los conceptos asociados a un plan de empresa, así como la utilización de simuladores empresariales y casos prácticos sobre experiencias empresariales reales.

\section{Propuestas relacionadas con las empresas de participación}

- Promover de forma específica la creación de sociedades cooperativas y sociedades laborales reforzando su carácter empresarial. Tomar un número mayor de iniciativas para divulgar los valores y principios cooperativos en el centro docente así como los principios inspiradores de la economía social.

- Incidir en las bondades de las sociedades cooperativas y laborales y establecer unos contenidos comunes en todo el Estado.
- Fomentar la difusión de los valores y principios del emprendimiento y de las empresas de participación entre padres y familiares habida cuenta de la correlación exitente entre dicho conocimiento y la valoración de los alumnos, organizando jornadas de puertas abiertas.

\section{Propuestas relacionadas con la valoración y eva- luación con respecto a los conocimientos adqui- ridos}

- Realizar encuestas de evaluación todos los años para valorar la formación sobre emprendimiento recibida.

- Reforzar la formación permanente del profesorado de modo que puedan organizarse cursos, jornadas y seminarios que procuren dar las claves de las materias más adecuadas para los alumnos.

- Incluir la enseñanza sobre emprendimiento y creación de empresas en los programas de formación inicial obligatoria del profesorado.

- Llevar a cabo el seguimiento del futuro profesional de los alumnos a través de la creación de una base de datos que podría coordinarse con la universidad para conocer en qué medida el esfuerzo en materia de emprendimiento está dando su frutos.

- Disponer de un simulador de empresas específico para los alumnos en el que se potencien las empresas de participación habida cuenta de que por falta de formación cualquier simulador o prescriptor externo no tendría en cuenta a las sociedades cooperativas y las sociedades laborales.

- Proponer una plataforma virtual de acceso para profesores y centros que constituya un centro de conocimiento virtual para incrementar su grado de involucración en asuntos relacionados con el emprendimiento y la creación de empresas; dicha plataforma permitiría compartir material didáctico, metodologías docentes, programas, actividades complementarias, experiencias de otros profesores y casos de buenas prácticas, así como poder contar con sistemas de apoyo, tales como personal especializado a quien poder realizar consultas.

Con todo, se ha de procurar:

- Vincular los instrumentos y herramientas de apoyo de los que se dispone en la universidad, al emprendimiento de los colegios para que se genere un hilo conductor de seguimiento y 
formación. En el caso concreto de la Universidad Complutense de Madrid, a través de la la Oficina Complutense del Emprendedor (Compluemprende), en lo general, y de la Escuela de Estudios Cooperativos, en el emprendimieno a través de empresas de participación.

- Crear una red de profesores de enseñanza primaria, secundaria, formación profesional y superior a través de la cual se difundan y conozcan las actividades que se desarrollan en materia de emprendimiento que dé lugar a la creación de las herramientas concretas propuestas en este estudio.

\section{Referencias}

Martín-López, S., Fernández-Guadaño, J., Bel-Durán, P. y Lejarriaga-Pérez De Las Vacas, G. (octubre, 2013). Necesidad de medidas para impulsar la creación de las empresas de participación desde los diferentes niveles de enseñanza. Ponencia presentada en el $4^{\circ}$ Congreso Internacional de Investigación en Economía Social del ciriec, Amberes (Bélgica).
Martín-López, S., Fernández-Guadaño, J., Bel-Durán, P. y Lejarriaga-Pérez De Las Vacas, G., García-Gutiérrez Fernández, C. (2013). Necesidad de medidas para impulsar la creación de las empresas de participación desde diferentes niveles de enseñanza. Revista $\mathrm{CI}^{-}$ RIEC-España, 78, 71-100.

Martín-López, S., Fernández-Guadaño, J., Bel-Durán, P., y Lejarriaga-Pérez De Las Vacas, G. (2014). La asignatura de iniciativa emprendendora en Enseñanza Secundaria como base para la creación de empresas de participación: un estudio en sociedades cooperativas de enseñanza. Ponencia presentada en el xv Congreso de Investigadores en Economía Social organizado por CIRIEC-España, Santander, España.

Martín-López, S., Fernández-Guadaño, J., Bel-Durán, P., Lejarriaga-Pérez De Las Vacas, G. y García-Gutiérrez Fernández, C. (2014). Un estudio sobre medidas necesarias para fomentar la creación de empresas de participación desde los diferentes niveles de enseñanza. Ponencia presentada en el xxxiI Seminario Nacional y XviI Seminario Internacional de investigación en materia de organizaciones de participación, Escuela de Estudios Cooperativos de la Universidad Complutense de Madrid, Madrid. 